\title{
The relationship between abdominal obesity and irritable bowel syndrome in adults
}

\author{
Yasemin DOGAN KAYA ${ }^{1}$ (D), Arzu UZUNER² (D) \\ ${ }^{1}$ Family Medicine, Jandarma Üsteğmen Rahim Çelik Family Health Center, Istanbul, Turkey. \\ ${ }^{2}$ Department of Family Medicine, School of Medicine, Marmara University Training and Research Hospital, Istanbul, Turkey.
}

Corresponding Author: Yasemin DOGAN KAYA

E-mail: dryaseminkaya@gmail.com

Submitted: 27.04.2021 Accepted: 10.09.2021

\begin{abstract}
Objective: The aim of this study is to evaluate the relationship between irritable bowel syndrome (IBS) and abdominal obesity. Patients and Methods: This is a cross-sectional study, consisting of 18-49 year old patients who applied to Marmara University School of Medicine's Family Medicine outpatient clinics and who accepted to participate. A questionnaire was applied using face-to-face interview technique; anthropometric measurements were obtained as recommended by World Health Organization (WHO). The diagnosis of IBS was made for those who fully met the diagnostic criteria of ROME IV-IBS and had no alarm symptoms. Abdominal obesity of the participants was determined via anthropometric measurements. Statistical analyses were performed by using SPSS 20 package program.

Results: A total of 487 patients participated in the study: 77\% female, 33\% male; mean age value $33.71 \pm 8.59$ years. The prevalence of IBS was 24.2\% ( $n=118)$ [F:27.2\% ( $n=102)$, M:14.3\% $(n=16)]$. Abdominal obesity prevalence was 31.2\% $(n=152)$ [F:24.5\% ( $=92$, M:53.6\% ( $n=60)$. There is no statistically significant difference in terms of abdominal obesity with and without IBS ( $p>0.05$ ).

Conclusion: In this study no statistically significant relationship has been detected between IBS and abdominal obesity.

Keywords: Irritable bowel syndrome, Abdominal obesity, Central obesity
\end{abstract}

\section{INTRODUCTION}

Irritable bowel syndrome (IBS) is a functional gastrointestinal disorder characterized by chronic abdominal pain and variable bowel habits and which affects the patient's quality of life negatively. The causes of IBS still remain unclear [1]. The prevalence of IBS is reported as 7 to $45 \%$ in different countries $[1,2]$; in Turkey this rate varies between $6.2 \%$ and $33.5 \%[3,4]$. IBS is more common and symptoms are more prominent in females $[1,2,5]$. IBS rarely begins after 60 years of age while its prevalence decreases after the fifties $[1,2,6]$. Although, the diagnosis can be easily made according to ROME IV criteria, the chronicity of the disease, and unrelieved and recurring symptoms cause patient dissatisfaction [1]. This leads to unnecessary consultations, unnecessary use of advanced diagnostic tests and medications, even interventions that lead to surgical operations which increase health expenditure and cause loss of labor [7]. Due to all these reasons and its high prevalence, IBS is one of the diseases that should be managed in primary care.

Abdominal obesity is also a global health problem, its prevalence is still increasing all over the world [8,9]. Intra-abdominal fat accumulation is known as the primarily responsible factor for increased mortality and morbidity, therefore, abdominal obesity is a significant indicator in terms of metabolic and cardiovascular risk factors $[10,11]$. The gold standard measurement methods of abdominal obesity are computerized tomography (CT), Dual-X-Ray and magnetic resonance imaging (MRI) $[12,13]$. These methods are not usable for primary care because of exposure to radiation, and furthermore they are expensive and difficult to access [14]. World Health Organization (WHO) recommends waist circumference as the cheapest, most accessible and closer result for determining abdominal obesity ( $\geq 104 \mathrm{~cm}$ for males, $\geq 88 \mathrm{~cm}$ for females) [10]. In recent years, the bioimpedance analysis (BIA) method which is based on the difference in lean tissue mass and the electrical permeability of adipose tissue has emerged as another safe, easily accessible and economical method to show abdominal obesity [15].

Some studies report an increasing risk of developing upper gastrointestinal system (GIS) symptoms in relation to increasing body mass index (BMI) [16-18], but the relationship between obesity and lower GIS symptomatology, especially IBS, remains unclear. Regarding the relationship between IBS and abdominal obesity, which is a commonly encountered clinical problem in

How to cite this article: Kaya Dogan Y, Uzuner A. The relationship between abdominal obesity and irritable bowel syndrome in adults. Marmara Med J 2022: 35(1):31-35. doi: 10.5472/marumj.1065778 
obesity, the evidence is still limited; only Lee et al's study suggests a relation between abdominal obesity and diarrhea dominant IBS (IBS-D), which implicates the need for more clinical studies [19]. The aim of this study is to evaluate the relationship between IBS and abdominal obesity.

\section{PATIENTS and METHODS}

\section{Study Type}

This is a cross-sectional study. The sample size has been calculated as 470 participants based on a confidence level of $95 \%$, acceptable error 3\%, and 13\% IBS prevalence which was accepted as the average percentage according to the other studies' results in the literature [1-4].

\section{The Universe of the Study and Recruitment of the participants}

The 18-49 years old patients who applied to the Marmara University Pendik Training and Research Hospital Tuzla and Maltepe Education Family Health Centers and University Family Medicine outpatient clinics with any complaint between October 2017 and February 2018, were accepted as the universe of the study. The patients were informed about the study by the researcher and by wall-posts. Interested patients were interviewed for inclusion criteria until the sample size was reached. A total of 487 patients were recruited for the study.

\section{Inclusion and Exclusion Criteria for the Study}

Inclusion criteria were: patients had to be between 18 and 49 years of age, as 50 and over 50 year olds counted as one of the alarm symptoms [20]; participation had to be voluntary, and there should be no communication barrier. Patients with a history of GIS diseases such as inflammatory bowel disease, lactose intolerance, colon cancer, celiac disease, gastrointestinal surgery; with diagnoses of psychiatric diseases such as schizophrenia, bipolar disorder; who were pregnant or having suspicion of pregnancy; who had mental and/or physical disabilities were excluded from the study. These disorders depended on the patients' own admissions.

\section{Data Collection Process}

Ethical approval was obtained from the Ethical Committee of Marmara University Clinical Studies dated 06.10.2017 with protocol no 09.2017.601 for the study entitled as "Relationship between abdominal obesity and irritable bowel syndrome in adults". All participants gave informed consent.

Data collection tools/ questionnaires utilized in this study were: 1. A questionnaire including sociodemographic information prepared by the researchers; 2. ROME IV-IBS diagnostic criteria, alarm symptoms $[1,20] ; 3$. Bristol Stool Scale used to differentiate subgroups $[1,20]$.

These questionnaires were applied to all of the participants using face to face interview technique by the researcher in outpatient clinics. Anthropometric measurements were: Height and waist circumference were measured according to the recommendations of the WHO, by the same researcher [10]. A constant-tension tape measure, a BIA device (Inbody 170, Seoul, Korea) and height meter were used for taking the measurements and BMI [weight $(\mathrm{kg}) /$ height $\left(\mathrm{m}^{2}\right)$ ] was calculated.

\section{Definition of abdominal obesity}

Abdominal obesity is defined based on waist circumference measurements according to the recommendations of the WHO. Cut-off values for abdominal obesity were defined as $\geq 104 \mathrm{~cm}$ for males, $\geq 88 \mathrm{~cm}$ for females by WHO. However, WHO recommends the use of cut-off values of their country to researchers, obtained from large scaled studies performed in the country [10]. In our study waist circumference cut-off values of Turkey Diabetes, Hypertension, Obesity and Endocrinological Diseases Prevalence Study (TURDEP II), a nationwide study realized with the participation of 26.499 Turkish adult people, were taken into consideration ( $\geq 90 \mathrm{~cm}$ for females, $\geq 96 \mathrm{~cm}$ for males) [9]. The other abdominal obesity measurement method in our study was BIA which provides high accuracy for visceral adipose tissue [14]. BIA device estimates the participants' trunk fat deposition individually as 'lean', 'normal' and 'over.' The participants determined 'over' for trunk fat by BIA device were accepted as abdominal obese.

\section{Definition of IBS}

Irritable bowel syndrome is defined according to the ROME IV diagnostic criteria including subgroup determination (constipation, diarrhoea, mixed and unclassified based on Bristol Stool Scale $[1,20]$ ) and excluding alarm symptoms such as iron deficiency anemia, rectal bleeding, unintentional weight loss, fever, changing bowel habits [20].

ROME IV criteria for IBS were: Recurrent abdominal pain, on average, at least 1 day/week in the last 3 months, associated with 2 or more of the following criteria: 1. Related to defecation, 2. Associated with a change in frequency of stool, 3 . Associated with a change in form (appearance) of stool. Criteria fulfilled for the last 3 months with symptom onset at least 6 months before diagnosis [20].

Irritable bowel syndrome is classified into four subgroups. Predominant bowel habits are based on stool form on days with at least one abnormal bowel movement. According to Bristol Stool Scale, $>25 \%$ type 1 or 2 stool form is accepted as constipationpredominant type (IBS-C), $>25 \%$ type 6 or 7 stool form is accepted as diarrhoea-predominant type (IBS-D), $>25 \%$ type 1 or 2 and $>25 \%$ type 6 or 7 stool forms are accepted as mixed type with constipation and diarrhoea (IBS-M). The other subgroup is unclassified type (IBS-U). This type complies with diagnostic criteria but does not meet other grouping standards [1].

\section{Statistical Analysis}

Statistical analysis was performed in SPSS version 20.0 for the Windows (IBM Corp.; Armonk, NY, USA) program. Frequency distribution, mean and median values of all independent variables were calculated; For comparisons between categorical variables Chi-Square test and $t$ test for continuing versus categorical variables were used. The statistical significance threshold was accepted as p value under 0.05 should be considered as significant. 


\section{RESULTS}

A total of 487 individuals participated in our study; $77 \%(s=375)$ female, $23 \%(n=112)$ male. The mean age of the participants was 33.7 \pm 8.6. Prevalence of IBS was determined as $24.2 \%(n=118)$; IBS subgroup prevalence was $39.8 \%(n=47)$ for IBS-C (constipationpredominant), $26.3 \%(\mathrm{n}=31)$ for IBS-U (unclassified), $24.6 \%(\mathrm{n}=29)$ for IBS-D (diarrhoea-predominant), 9.3\% $(n=11)$ for IBS-M (mixed type). Sociodemographic and health related characteristics of IBS and non-IBS groups and their comparative analysis results are summarized in Table I. There was a statistically significant difference between the two groups only in terms of gender and fibromyalgia. IBS was more prevalent in females; fibromyalgia was more prevalent in participants with IBS ( $\mathrm{p}=0.003, \mathrm{p}=0.033$, respectively).

Table I. Sociodemographic and health related characteristics and comparison between groups of participants with and without IBS

\begin{tabular}{|c|c|c|c|c|c|c|c|c|}
\hline \multirow{2}{*}{\multicolumn{2}{|c|}{ Characteristics }} & \multicolumn{2}{|c|}{$\mathrm{IBS}(+)$} & \multicolumn{2}{|c|}{ IBS(-) } & \multicolumn{2}{|c|}{ Total } & \multirow[b]{2}{*}{$\mathrm{p}^{*}$} \\
\hline & & $\mathrm{n}$ & $\%$ & $\mathrm{n}$ & $\%$ & $\mathrm{n}$ & $\%$ & \\
\hline \multicolumn{9}{|l|}{ Gender } \\
\hline \multicolumn{2}{|l|}{ Female } & 102 & 27.2 & 273 & 72.8 & 375 & 100.0 & \multirow[t]{2}{*}{0.003} \\
\hline \multicolumn{2}{|l|}{ Male } & 16 & 14.3 & 96 & 85.7 & 112 & 100.0 & \\
\hline \multicolumn{9}{|l|}{ Age groups } \\
\hline \multicolumn{2}{|l|}{$18-24$ years } & 18 & 19.6 & 74 & 80.4 & 92 & 100.0 & \multirow{3}{*}{0.674} \\
\hline \multicolumn{2}{|l|}{ 25-34 years } & 47 & 27.5 & 124 & 72.5 & 171 & 100.0 & \\
\hline \multicolumn{2}{|l|}{$35-49$ years } & 53 & 23.7 & 171 & 76.3 & 224 & 100.0 & \\
\hline \multicolumn{9}{|l|}{ Marital status } \\
\hline \multicolumn{2}{|l|}{ Married } & 83 & 25.9 & 238 & 74.1 & 321 & 100.0 & \multirow[t]{2}{*}{0.146} \\
\hline \multicolumn{2}{|l|}{ Single } & 35 & 21.1 & 131 & 78.9 & 166 & 100.0 & \\
\hline \multicolumn{9}{|l|}{ Education } \\
\hline \multicolumn{2}{|c|}{$\begin{array}{l}\text { Secondary school and } \\
\text { below }\end{array}$} & 28 & 21.2 & 104 & 78.8 & 132 & 100.0 & \multirow[t]{2}{*}{0.204} \\
\hline \multicolumn{2}{|c|}{ High school and above } & 90 & 25.4 & 265 & 74.6 & 355 & 100.0 & \\
\hline \multicolumn{9}{|l|}{ Employment } \\
\hline \multicolumn{2}{|l|}{ Employed } & 75 & 24.8 & 227 & 75.2 & 302 & 100.0 & \multirow[t]{2}{*}{0.388} \\
\hline \multicolumn{2}{|l|}{ Unemployed } & 43 & 23.2 & 142 & 76.8 & 142 & 100.0 & \\
\hline \multicolumn{9}{|l|}{ Income status } \\
\hline$\leq 1404 \mathrm{TL}$ & & 28 & 25.9 & 80 & 74.1 & 108 & 100.0 & \\
\hline $1404-4890 \mathrm{TL}$ & & 78 & 25.8 & 224 & 74.2 & 302 & 100.0 & 0.143 \\
\hline$\geq 4891 \mathrm{TL}$ & & 12 & 15.6 & 65 & 84.4 & 77 & 100.0 & \\
\hline Medical history & & & & & & & & \\
\hline Hypertension & & 4 & 3.4 & 18 & 4.9 & 22 & 4.5 & 0.349 \\
\hline Diabetes & & 6 & 5.1 & 17 & 4.6 & 23 & 4.7 & 0.499 \\
\hline Cardiovascular & eases & 3 & 2.5 & 14 & 3.8 & 17 & 3.5 & 0.377 \\
\hline Hypothyroidism & & 10 & 8.5 & 33 & 8.9 & 43 & 8.8 & 0.523 \\
\hline Depression & & 8 & 6.8 & 17 & 4.6 & 25 & 5.1 & 0.239 \\
\hline Upper GI diseas & & 22 & 18.6 & 54 & 14.6 & 76 & 15.6 & 0.183 \\
\hline Fibromyalgia & & 4 & 3.4 & 2 & 0.5 & 6 & 1.2 & 0.033 \\
\hline Smoking status & Never & 66 & 55.9 & 230 & 62.3 & 296 & 60.8 & 0.346 \\
\hline & Former & 19 & 16.1 & 43 & 11.7 & 62 & 12.7 & \\
\hline & Current & 33 & 28.0 & 96 & 26.0 & 129 & 26.5 & \\
\hline Alcohol & Yes & 15 & 12.7 & 46 & 12.5 & 61 & 12.5 & 0.527 \\
\hline & No & 103 & 87.3 & 323 & 87.5 & 426 & 87.5 & \\
\hline Total & & 118 & 24.2 & 369 & 75.8 & 487 & 100.0 & \\
\hline
\end{tabular}

${ }^{*}$ Chi-Squared test, $p<0.05$
The abdominal obesity frequency in IBS and non-IBS participants and their comparative analysis according to TURDEP II, WHO cut-off values and BIA results are summarized in Table II.

Table II. Abdominal obesity according to TURDEP II, WHO, BIA and their comparative analyses in IBS and non-IBS groups

\begin{tabular}{lcccccccc} 
Abdominal & & \multicolumn{2}{c}{ IBS (+) } & \multicolumn{2}{c}{ IBS (-) } & \multicolumn{2}{c}{ Total } & \\
Obesity for & & $\mathrm{n}$ & $\%$ & $\mathrm{n}$ & $\%$ & $\mathrm{n}$ & $\%$ & $\mathrm{p}^{*}$ \\
\hline \multirow{2}{*}{ TURDEP II } & $(+)$ & 38 & 32.2 & 114 & 30.9 & 152 & 31.2 & 0.436 \\
\cline { 2 - 10 } & $(-)$ & 80 & 67.8 & 255 & 69.1 & 335 & 68.8 & \\
\hline \multirow{2}{*}{ WHO } & $(+)$ & 14 & 11.9 & 63 & 17.1 & 77 & 15.8 & 0.112 \\
\cline { 2 - 10 } & $(-)$ & 104 & 88.1 & 306 & 82.9 & 410 & 84.2 & \\
\hline BIA & $(+)$ & 89 & 75.4 & 285 & 77.2 & 374 & 76.8 & 0.385 \\
\cline { 2 - 9 } & $(-)$ & 29 & 24.5 & 84 & 22.8 & 113 & 23.2 & \\
\hline Total & & 118 & 100.0 & 369 & 100.0 & 487 & 100.0 & \\
\hline
\end{tabular}

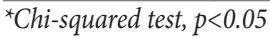

IBS: Irritable bowel syndrome, TURDEP II: Turkey Diabetes, Hypertension, Obesity and Endocrinological Diseases Prevalence Study, WHO: World Health Organization, BIA: Bioimpedance analysis

Participants with and without IBS were compared as to whether there was a difference in terms of mean waist circumference $(\mathrm{cm})$. There was no statistically significant difference between the groups ( $\mathrm{p}>0.05)$.

No statistically significant relationship was detected between IBS and IBS subgroups and GIS symptoms except constipation. The results are summarized in Table III.

Table III. Comparison of IBS subgroups and GIS symptoms with abdominal obesity

\begin{tabular}{|l|c|c|c|c|c|c|c|}
\hline \multirow{2}{*}{$\begin{array}{l}\text { IBS subgroups and GIS } \\
\text { symptoms }\end{array}$} & \multicolumn{7}{|c|}{ Abdominal obesity } \\
\cline { 2 - 8 } & $\mathrm{n}$ & $\%$ & $\mathrm{n}$ & $\%$ & $\mathrm{n}$ & $\%$ & $\mathrm{p}^{*}$ \\
\hline IBS-C & 17 & 63.8 & 30 & 36.2 & 47 & 100.0 & 0.290 \\
\hline IBS-D & 10 & 65.5 & 19 & 34.5 & 29 & 100.0 & 0.465 \\
\hline IBS-M & 1 & 9.1 & 10 & 90.9 & 11 & 100.0 & 0.076 \\
\hline IBS-U & 10 & 32.3 & 21 & 67.7 & 31 & 100.0 & 0.581 \\
\hline Constipation & 68 & 27.4 & 180 & 72.6 & 248 & 100.0 & 0.041 \\
\hline Diarrhoea & 50 & 28.2 & 127 & 71.8 & 177 & 100.0 & 0.167 \\
\hline Nausea & 52 & 29.1 & 127 & 70.9 & 179 & 100.0 & 0.248 \\
\hline Vomiting & 18 & 25.7 & 52 & 74.3 & 70 & 100.0 & 0.176 \\
\hline Bloating & 100 & 31.6 & 216 & 68.4 & 316 & 100.0 & 0.431 \\
\hline Pain during defecation & 48 & 27.7 & 125 & 72.3 & 173 & 100.0 & 0.130 \\
\hline
\end{tabular}

IBS: Irritable bowel syndrome, GIS: Gastrointestinal system, IBS-C: Irritable bowel syndrome with predominant constipation, IBS-D: Irritable bowel syndrome with predominat diarrhoea, IBS-M: Irritable bowel syndrome-mixed type, IBS-C: Irritable bowel syndrome-unclassified type

\section{DISCUSSION}

According to the results of our study, no relationship between abdominal obesity and IBS was detected; there was no statistically significant difference between the IBS and IBS subgroups and non-IBS groups in terms of abdominal obesity. 
Lee et al., had reported that abdominal obesity was related to an increased risk of IBS in IBS-D subgroup [19]. In their study, abdominal obesity was measured by CT which was a part of the routine health control in this country. CT is accepted as a gold standard method for the diagnosis of abdominal obesity. However, as it is expensive, not easily accessible and because of exposure to radiation, it is not a preferred method for primary care patients [14]. The main difference between Lee et al.s and our study may be due to the use of different diagnostic methods. WHO recommends the measurement of waist circumference as the cheapest, more accessible and closest to the ideal method to determine abdominal obesity [10]. In our study abdominal obesity is defined based on waist circumference measurement and the BIA; no statistically significant difference was detected between the IBS and IBS subgroups and non-IBS groups in terms of abdominal obesity, using both measurements.

Computerized tomography was also used in the clinical trial of Nagata et al., evaluating the relation between bowel symptoms and visceral fat tissue. It was determined that the risk of constipation and hard stools was related to low visceral adipose tissue (VAT) and low subcutaneous adipose tissue (SAT), which are criteria for abdominal fat deposition and equally mean abdominal obesity [21]. In our study, complaint of hard stools/constipation and/or being in IBS-C subgroup were not significantly related to the presence of abdominal obesity.

Prevalence of IBS was detected as $24.2 \%$ in our study. In a metaanalysis of 80 studies, the world-wide prevalence of IBS was reported as $11.2 \%(1 \%-45 \%)$ [1]. In the studies performed in Turkey this prevalence varied from $6.3 \%$ to $33.5 \%[3,4]$. As for the subgroups, in our study IBS-C was the most prevalent form similarly to the meta-analysis of Lovell et al. [2]. In our country, although, the prevalence of IBS subgroups differed among studies, IBS-C was the most commonly detected subgroup $[3,4]$.

Based on clinical studies, IBS is related to several factors such as female gender, psychiatric disorders, fibromyalgia, GIS tract disorders [22,23]. There is evidence of the relation between abdominal obesity and factors such as female gender and upper GIS disorders $[9,24]$. In our study a comparison of IBS and nonIBS groups was made in terms of these factors.

Irritable bowel syndrome was significantly more prevalent in female participants $(27.2 \%)$ than in males $(14.3 \%)$ similar to the literature [5]. The prevalence of IBS was higher in participants with a higher educational level, but this difference was not statistically significant. According to the results of different studies, the relationship between IBS prevalence and education level is contradictory. In other studies from different countries, the results were similar or there was a linear relation between them [25]. In our country, the increased prevalence of IBS was reported in relation to lower education level [3].

According to the health characteristics of the participants, upper gastrointestinal diseases such as gastro-esophageal reflux disease, peptic ulcer and gastritis, diabetes and depression were more frequent in the IBS group, but this result was not statistically significant. Only fibromyalgia was significantly more prevalent in the IBS group, which is compatible with literature [23].
Concerning smoking status, however, IBS was more frequently detected among participants who never smoked, there was no statistical significance. IBS was more prevalent among participants who used alcohol, which was still not statistically significant. Reding et al., in their study examining the relation of alcohol use in IBS individuals with gastrointestinal symptoms, stated that the effect of alcohol use in IBS individuals on gastrointestinal symptoms is still unclear [26].

The strengths of the study; anthropometric measurements and questionnaire were applied by a single physician with a standard approach. It was performed using two different waist circumference cut-off values and the BIA method which supported both results.

The limitations of this study may be summarized in two items. Firstly, the history of their diseases and medication use was based on the patients' own revelations, not on laboratory results. Secondly, some health problems such as hypothyroidism, diabetes which can alter gastrointestinal functions, were not excluded from the study since this study was performed in primary care clinics where the patients are frequently multimorbid and they apply with an undifferentiated complaint so that it was difficult to find an isolated IBS patient.

In conclusion, the main outcome of the study was no statistically significant relationship between IBS and abdominal obesity. The social and health determinants related to IBS, female gender, depression and fibromyalgia were in significant relation with abdominal obesity which can be perceived as supporting the main result.

\section{Compliance with the Ethical Standards}

Ethical Approval: Ethical approval was obtained from the Ethical Committee of Marmara University Clinical Studies dated 06.10.2017 with protocol no 09.2017.601 All participant gave written informed consent.

Financial Support: The authors have no relevant financial information to close.

Conflict of Interest: The authors have no potential conflicts of interest to disclose

Author Contributions: YDK and AU: Conceived and planned the study, YDK: Collected and analyzed the data, YDK : Wrote the first draft of the manuscript. Both authors contributed to the interpretation of findings and reviewed the manuscript. They read and approved the final version of the article.

\section{REFERENCES}

[1] Heidelbaugh J, Hungin P, Guest Eds, editors. Drossman DA, Chang L, Kellow J, Chey WD, Tack J, Whitehead WE, editors. The Rome IV Primary Care Committee. Rome IV functional gastrointestinal disorders for primary care and non-GI clinicians. 1st ed. Raleigh, NC: The Rome Foundation, 2016.

[2] Lovell RM, Ford AC. Global prevalence of and risk factors for irritable bowel syndrome: a meta-analysis. Clin Gastroenterol Hepatol 2012 ;10:712-1. doi:10.1016/j.cgh.2012.02.029 
[3] Celebi S, Acik Y, Deveci SE, et al.Epidemiological features of irritable bowel syndrome in a Turkish urban society. J Gastroenterol Hepatol 2004;19:738-43. doi: 10.1111/j.14001746.2004.03367.x

[4] Özden A, Köksal ŞA, Oğuz D, et al. Türkiye’de birinci basamak sağlık kurumlarında irritabl barsak sendromu görülme sıklı̆̆ı. Akademik Gastroenteroloji Dergisi 2006; 5: 4-15.

[5] Lee OY, Mayer EA, Schmulson M, Chang L, Naliboff B. Genderrelated differences in IBS symptoms. Am J Gastroenterol 2001;96:2184-93. doi:10.1016/S0002-9270(01)02524-2

[6] Bennett G, Talley NJ. Irritable bowel syndrome in the elderly. Best Pract Res Clin Gastroenterol 2002 ;16:63-76. doi:10.1053/ bega.2001.02661

[7] Longstreth GF, Wilson A, Knight K, et al. Irritable bowel syndrome, health care use, and costs: a U.S. managed care perspective. Am J Gastroenterol 2003;98:600-7. doi:10.1016/ S0002-9270(02)06018-5

[8] Obezite, T. E. M. D., ve Hipertansiyon Çalışma Grubu. Obezite tanı ve tedavi kılavuzu. Türkiye Endokrinoloji ve Metabolizma Derneği. Ankara: Tipkı Basım, 2017: 11-19.

[9] Satman I, Omer B, Tutuncu Y, et al. Twelve-year trends in the prevalence and risk factors of diabetes and prediabetes in Turkish adults. Eur J Epidemiol 2013;28:169-80. doi: 10.1007/ s10654.013.9771-5

[10] World Health Organization. Waist circumference and waisthip ratio : report of a WHO expert consultation, Geneva, 8-11 December 2008. World Health Organization 2011. Available at: https://apps.who.int/iris/handle/10665/44583 Accessed on: 27.09.2021

[11] Balkau B, Deanfield JE, Després JP, et al. International Day for the Evaluation of Abdominal Obesity (IDEA): a study of waist circumference, cardiovascular disease, and diabetes mellitus in 168,000 primary care patients in 63 countries. Circulation 2007;116:1942-51. doi: 10.1161/circulationaha.106.676379

[12] John BJ, Irukulla S, Abulafi AM, Kumar D, Mendall MA. Systematic review: adipose tissue, obesity and gastrointestinal diseases. Aliment Pharmacol Ther 2006;23: 1511-23. doi: 10.1111/j.1365-2036.2006.02915.x

[13] Liu P, Ma F, Lou H, Liu Y.The utility of fat mass index vs.body mass index and percentage of body fat in the screening of metabolic syndrome. BMC Public Health 2013:13:629. doi: 10.1186/1471-2458-13-629.

[14] Yamakage $H$, Ito $R$, Tochiya $M$, et al. The utility of dual bioelectrical impedance analysis in detecting intra-abdominal fat area in obese patients during weight reduction therapy in comparison with waist circumference and abdominal CT. Endocr J 2014;61:807-19.doi: 10.1507/endocrj.ej14-0092

[15] Gómez-Ambrosi J, González-Crespo I, Catalán V, et al. Clinical usefulness of abdominal bioimpedance (ViScan) in the determination of visceral fat and its application in the diagnosis and management of obesity and its comorbidities, Clin Nutr 2018 ;37:580-9. doi: 10.1016/j.clnu.2017.01.010.

[16] Le Pluart D, Sabaté JM, Bouchoucha M, Hercberg S, Benamouzig R, Julia C. Functional gastrointestinal disorders in 35,447 adults and their association with body mass index. Aliment Pharmacol Ther 2015;41:758-67. doi: 10.1111/ apt.13143

[17] Ho W, Spiegel BM. The relationship between obesity and functional gastrointestinal disorders: causation, association, or neither? Gastroenterol Hepatol (N Y) 2008;4:572-8.

[18] Pickett-Blakely O. Obesity and irritable bowel syndrome: a comprehensive review. Gastroenterol Hepatol (N Y) 2014;10:411-6.

[19] Lee CG, Lee JK, Kang YS, et al. Visceral abdominal obesity is associated with an increased risk of irritable bowel syndrome. Am J Gastroenterol 2015;110:310-9.doi: 10.1038/ajg.2014.422.

[20] Whitehead EE, Palsson OS, MALvT, Sperber A, BS, Tack J, Walker LS, YY . The Rome IV Committees, editors. Development and validation of the ROME IV diagnostic questionnaires. In: Drossman DA, Chang LC, Kellow WJ, Tack J, Whitehead WE, editors. ROME IV diagnostic questionnaires and tables for investigators and clinicians. Raleigh, NC: The Rome Foundation, 2016: 43-92.

[21] Nagata N, Sakamoto K, Arai T, et al. Effect of body mass index and intra-abdominal fat measured by computed tomography on the risk of bowel symptoms. PLoS One 2015 23;10:e0123993. doi:10.1371/journal.pone.0123993

[22] Whitehead WE, Palsson O, Jones KR. Systematic review of the comorbidity of irritable bowel syndrome with other disorders: what are the causes and implications? Gastroenterology 2002; 122: 1140-56. doi: 10.1053/gast.2002.32392

[23] Hausteiner-Wiehle C, Henningsen P. Irritable bowel syndrome: relations with functional, mental, and somatoform disorders. World J Gastroenterol 2014;20:6024-30. doi: 10.3748/wjg.v20. i20.6024

[24] Nam SY, Choi IJ, Ryu KH, Park BJ, Kim HB, Nam BH. Abdominal visceral adipose tissue volume is associated with increased risk of erosive esophagitis in men and women. Gastroenterology 2010;139:1902-11.e2. doi: 10.1053/j. gastro.2010.08.019

[25] Carter D, Beer-Gabel M, Tzur D, et al. Predictive factors for the diagnosis of irritable bowel syndrome in a large cohort of 440,822 young adults. J Clin Gastroenterol 2015;49:300-5. doi: 10.1097/mcg.000.000.0000000114

[26] Reding KW, Cain KC, Jarrett ME, Eugenio MD, Heitkemper MM. Relationship between patterns of alcohol consumption and gastrointestinal symptoms among patients with irritable bowel syndrome. Am J Gastroenterol 2013;108:270-6. doi: 10.1038/ajg.2012.414 